\title{
复 \\ Utilização de 5-fluorouracil (5-FU) tópico em equino com carcinoma de célula epidermoide: relato de caso
}

[Use of topical 5-fluorouracil (5-FU) on equine epidermoid cell carcinoma: a case report]

\section{"Relato de Caso/Case Report"}

\author{
Antônio Catunda Pinho Neto ${ }^{1}$, Vivian Viana ${ }^{2}$, Magda Lima Chagas Araújo ${ }^{2}$, \\ Thaire Pereira Maróstica $^{1}$, Debora da Silva Freitas Ribeiro ${ }^{3}$, Rodrigo Martins Ribeiro ${ }^{3 *}$
}

\author{
${ }^{1}$ Departamento de Medicina Veterinária, Universidade Federal de Minas Gerais, Belo Horizonte-MG, Brasil. \\ ${ }^{2}$ Curso de Medicina Veterinária, INTA, Sobral-CE, Brasil. \\ ${ }^{3}$ Curso de Medicina Veterinária, Centro Universitário de Mineiros, Mineiros-GO, Brasil. \\ *Autor para correspondência/Corresponding author: E-mail: vetrodrigo@msn.com
}

\section{Resumo}

O carcinoma de células escamosas ou epidermoide (CCE) é um uma neoplasia maligna, multifatorial, de origem epidérmica, comum em equinos e responsável por $20 \%$ dos tumores dessa espécie. Nesse contexto, o 5-fluorouracil atua na síntese de DNA e RNA por inibição enzimática, interferindo na replicação celular, sendo indicado nos casos em que há lesões pequenas. Pode ser administrado por via parenteral, tópica ou por injeção intratumoral. O presente trabalho tem como objetivo registrar a ocorrência de um caso de CCE em um equino com lesão ulcerativa extensa apresentando secreção sanguinolenta e purulenta, na região torácica, bem como a evolução do tratamento com o 5-fluorouracil, quimioterapia antineoplásica neoadjuvante, para a remissão da lesão e reduzir a área a ser extirpada com margem de segurança.

Palavras-chave: neoplasia; cavalo; quimioterapia.

\begin{abstract}
Squamous cell carcinoma (SCC) is a multifactorial malignant neoplasm of epidermal origin, common in horses and responsible for $20 \%$ of equine skin tumors. In this context, 5-fluorouracil acts in the synthesis of DNA and RNA by enzymatic inhibition, interfering in cellular replication, being indicated in cases in which there are small lesions. It can be administered parenterally, topically, or by intratumoral injection. This study aims to record the occurrence of SCC in an equine with an extensive ulcerative lesion with bloody and purulent secretion located in the thoracic region, as well as the evolution of 5-fluorouracil treatment, neoadjuvant antineoplastic chemotherapy for remission of the lesion and to reduce the area to be excised as a safety margin.
\end{abstract}

Keywords: neoplasia; horse; chemotherapy.

\section{Introdução}

O carcinoma de células escamosas ou epidermoide (CCE) é uma neoplasia maligna de origem epidérmica, comum em cavalos e responsável por $20 \%$ dos tumores de pele dos equinos (Robson e Sprayberry, 2008). Muitos são os fatores associados ao desenvolvimento de CCE, incluindo a exposição prolongada à luz ultravioleta, falta de pigmento na epiderme, perda ou cobertura de pelos muito esparsa nos locais afetados. As regiões do corpo de maior ocorrência são as pálpebras, prepúcio, vulva, cicatrizes, queimaduras e feridas não cicatrizadas com infecção crônica (Scott e Miller, 2004).

Dentre as diversas modalidades de terapias antineoplásicas, os quimioterápicos são classificados conforme sua estrutura química, sendo elas: alquilantes, agentes antimetabólicos, antibióticos antitumorais, nitrosureias, alcaloides da vinca, agentes hormonais e agentes diversos (Clark e McGee, 1997).

O 5-fluorouracil é um quimioterápico do grupo dos antimetabólitos que é convertido 
intracelular em vários compostos, os quais atuam no RNA da célula inibindo a síntese de timidilatosintase, uma enzima necessária para a replicação do DNA e reparo, debilitando o crescimento das células neoplásicas (Clark e McGee, 1997).

A terapia com 5-fluorouracil é recomendada em lesões pequenas ou quando não há possibilidade de se utilizar outro tipo de tratamento (Goodrich et al., 1998). É comumente utilizado pela via parenteral, também sendo descrita a utilização local como pomada ou injeção intratumoral. O custo da terapia com 5-fluorouracil tópico é relativamente baixo e esse quimioterápico apresenta baixa toxicidade inespecífica, provocando apenas mielotoxicidade discreta (Ferreira et al., 2006). Os estágios do tratamento com 5-fluorouracil são semelhantes aos descritos em humanos, embora sejam mais curtos em equinos (Scott e Miller, 2003).

O objetivo deste relato de caso é descrever a evolução do tratamento de um equino com CCE que foi tratado com o antineoplásico 5-fluorouracil e posterior excisão cirúrgica.

\section{Descrição do Caso}

Um equino, garanhão, com nove anos, sem raça definida, de pelagem leoparda foi atendido pelo Hospital Veterinário de Grandes Animais da Faculdade INTA (Instituto Superior de Teologia Aplicada), localizado na cidade de Sobral, Ceará, com queixa de uma ferida na caixa torácica esquerda que não cicatrizava (Figura 1). No relato do proprietário, o paciente habitava local úmido e convivia com outros animais apresentando lesões semelhantes, no qual um deles veio a óbito.

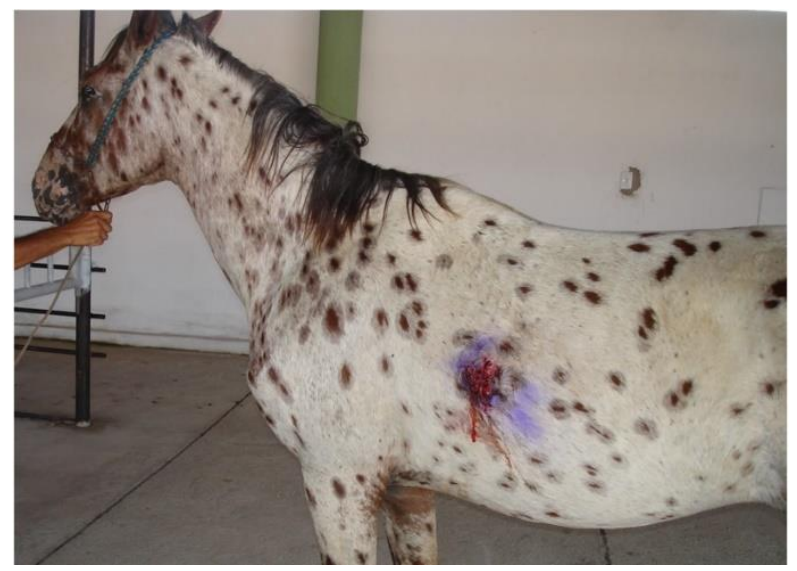

Figura 1. Equino atendido no Hospital Veterinário de Grandes Animais da Faculdade INTA, apresentando lesão ulcerativa diagnosticada como carcinoma de células epidermoide.
Durante o exame físico não foram encontradas alterações dignas de nota, exceto pela lesão ulcerativa, com bordas irregulares, tecido de granulação exuberante e secreção sanguinolenta localizada na região torácica esquerda, entre o $8^{\circ} \mathrm{e}$ $13^{\circ}$ espaço intercostal. Foi feita uma biopsia da ferida para a realização de exame histopatológico, o qual foi constatado CCE bem diferenciado. O tratamento de escolha para esse caso foi utilizar quimioterápico 5 -fluorouracil a 5\% tópico para a remissão do tumor e posterior excisão cirúrgica com margem de segurança.

$\mathrm{O}$ tratamento utilizado prévio à quimioterapia foi curativo diário local com aplicação tópica de pomada antisséptica e administração de penicilina G procaína (Agrovet 5.000.000 ${ }^{\circledR}(20.000 .000 \mathrm{UI} / \mathrm{IM} / \mathrm{SID})$ durante dez dias. Após sete dias foi iniciado o tratamento com o quimioterápico 5-fluorouracil a 5\% manipulado em farmácia de manipulação, administrado por via tópica, BID, após prévia limpeza com clorexidine a $0,1 \%$ (Riohex Rioquimica ${ }^{\circledR}$ ) (Ferreira et al., 2006).

No sétimo dia após o início do tratamento com o quimioterápico, detectou-se presença de tecido inflamatório. Durante o tratamento houve aumento da lesão, proliferação celular com processo inflamatório evidente, presença de secreção purulenta e necrose na região da lesão. Após 95 dias foram observadas descamação e redução da lesão, demonstrando regressão da neoplasia (Figura 2). No $140^{\circ}$ dia a lesão apresentava regressão significativa, com diminuição da secreção, possibilitando a excisão cirúrgica obedecendo a margem de segurança de 3 $\mathrm{cm}$ ao redor da lesão, com o intuito de reduzir as chances de recidiva tumoral.

Foi constatada descamação do tecido localizado ventral à lesão principal, devido à descida por ação gravitacional do quimioterápico sobre o tecido saudável, levando a uma ação degenerativa do medicamento nessa região (Figura 3). Após o procedimento de excisão cirúrgica com margem de segurança de $3 \mathrm{~cm}$ ao redor da lesão, o animal ficou internado para o tratamento da ferida cirúrgica durante trinta dias, recebendo alta sem apresentar recidiva do tumor.

\section{Discussão}

O CCE tem sido relatado como o segundo tumor mais comum em equinos e, na maioria das vezes, afeta tecidos perioculares, genitais, estômago e pele (Sundberg, 1977; Moore et al., 
2003). A radiação ultravioleta pode ser o fator causal, já que comumente o CCE é observado em tecidos despigmentados (MacFadden e Pace, 1991; Moore et al., 2003), como no caso em estudo, o qual o tumor observado na região despigmentada entre os espaços intercostais $8^{\circ}$ e $13^{\circ}$, corroborando com os achados clínicos de Dória et al. (2012), em que o paciente apresentava CCE na região despigmentada entre as narinas e lábio superior.

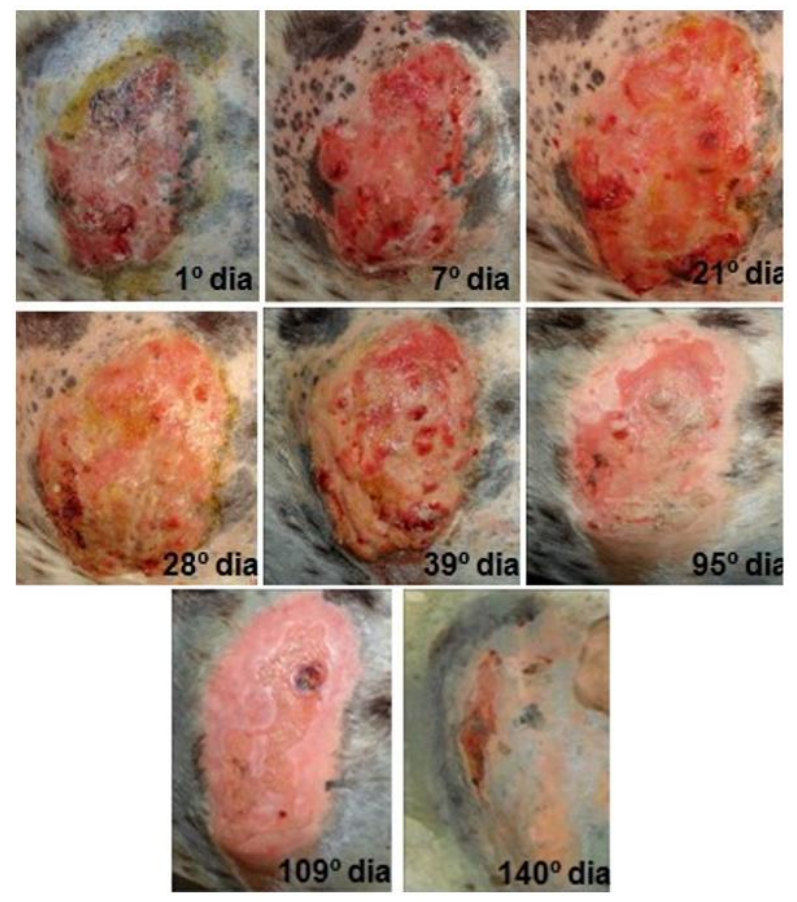

Figura 2. Aspecto macroscópico da evolução do tratamento de equino acometido por carcinoma de células epidermoide tratado com 5-fluorouracil 5\% tópico em função do tempo (dias), demonstrando a evolução do tratamento.

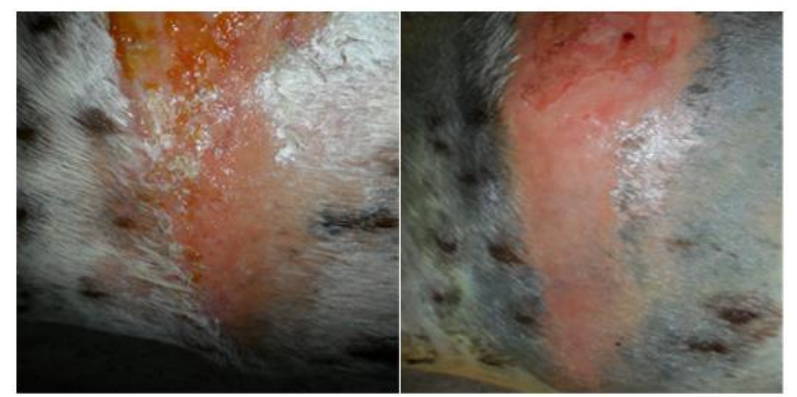

Figura 3. Reação de pele em tecido adjacente causada pelo uso do 5-fluourouracil a 5\% tópico em tumor diagnosticado como carcinoma de células epidermoide em equino.

O tratamento com quimioterápico é classificado como neoadjuvante, terapêutico e adjuvante (Chu e Devita, 2001). O quimioterápico 5-fluorouracil foi utilizado no paciente em questão como medida terapêutica neoadjuvante para posterior remoção cirúrgica do tumor. Essa terapia inicial em pacientes que serão submetidos a processo cirúrgico ou radioterápico, tem a finalidade de diminuir o tumor, tornando possível a cirurgia ou possibilitando menor mutilação no processo cirúrgico (Anelli, 2002; Gimenez et al., 2003).

As substâncias mais utilizadas no tratamento de tumores são a bleomicina, a cisplatina, mitomycina-C e o 5-fluorouracil (Lloyd et al., 2003; Scott e Miller, 2003). O 5-fluorouracil foi o medicamento escolhido por oferecer vantagens diretas na administração da quimioterapia como níveis de concentração sistêmica mínima da droga e mínimos efeitos colaterais sistêmicos, além de ser economicamente viável sua utilização, uma vez que a cisplatina e bleomicina possuem um valor relativamente elevado, tornando-se limitada sua utilização nos pacientes (Pucket e Gilmour, 2011).

Outra vantagem do 5-fluorouracil é que ele se apresenta como uma forma alternativa para a terapia com quimioterápico intralesional, não exigindo preparação especializada ou equipamento para ser manipulado (Pucket e Gilmour, 2011).

$\mathrm{O}$ tratamento escolhido para esse animal apresentou como desvantagem sua longa duração e o processo inflamatório cutâneo na região da ferida, concordando com Nogueira et al. (2006), que observaram os mesmos efeitos colaterais, como reações cutânea nos locais de tratamento e em tecidos adjacentes, alopecia, eritema, despigmentação, edema, erosão, ulceração, descamação e exsudação.

\section{Conclusão}

O tratamento com 5-fluouracil tópico mostrou-se eficaz no caso apresentado, promovendo a regressão do tumor possibilitando sua posterior excisão, e apresentou um produto de fácil manipulação, tendo como desvantagem o tratamento de longa duração e sua reatividade no tecido das regiões circunvizinhas à lesão principal.

\section{Conflito de Interesse}

Os autores declaram não existir conflito de interesse.

\section{Referências}

Anelli, A. Tratamento sistêmico do câncer. In: Kowaslki, L.P.; Anelli, A.; Salvajoli, J.V.; Lopes, L.F. Manual de condutas diagnósticas e terapêuticas em oncologia. $2^{\mathrm{a}}$ ed. São Paulo: Âmbito Editores Ltda, 2002. p. 100-111. 
Chu, E.; DeVita, V.T.J. Principles of cancer management: chemotherapy. In: DeVita, V.T.J.; Helmans, S.; Rosember, S.A. Cancer: principles e practice of oncology. $6^{\text {th }}$ ed. Philadelphia: Lippincott. Willians \& Wilkins, 2001. p. 289-306p.

Clark, J.C.; McGee, R.F. Enfermagem oncológica: um curriculum básico. $2^{\mathrm{a}}$ ed. Porto Alegre: Artes Médicas, 1997. 586p.

Ferreira, I.; Rahal, S.C.; Ferreira, J.; Corrêa, T.P. Terapêutica no carcinoma de células escamosas cutâneo em gatos. Ciência Rural, 36(3): 1027-1033, 2006.

Gimenez, D.L.; Quimioterapia. In: Ikemori, E.H.A.; Oliveira, T.; Serralheiro, I.F.D.; Shibuya, E.; Cotrim, T.H.; Trinti, L.A. Nutrição em oncologia $1^{a}$ ed. São Paulo: Lemar, 2003. p.178-188p.

Goodrich, L.; Gerber, H.; Marti, E.; Antczak, D.F. Equine sarcoids. Veterinary Clinics of North America: Equine Practice, 14: 607-623, 1998.

Lloyd, D.H.; Littlewood, J.D.; Craig, J.M.; Thonmsett, L.R. Nodules and swelling. In: Practical equine dermatology. Iowa: Blackwell Science Ltda, 2003. p. 63-99

Macfadden, K.E.; Pace, L.W. Clinical manifestations of squamous cell carcinoma in horses. The Compendium on Continuing Education for the Practicing Veterinarian, 13(4): 669-677, 1991.
Moore, A.S.; Beam, S.L.; Rassnick, K.M.; Provost, P. Long-term control of mucocutaneous squamous cell carcinoma and metastases in a horse using piroxicam. Equine Veterinary Journal, 35(7): 715-718, 2003.

Nogueira, S.A.F.; Torres, S.M.F.; Malonet, E.D.; Diaz, S.F.; Jessen, C.; Gilbert, S. Efficacy of imiquimod $5 \%$ cream in the treatment of equine sarcoids: a pilot study. European Society of Veterinary Dermatology, 17: 259-265, 2006.

Pucket, J.D.; Gilmour, M.A. Intralesional 5fluorouracil (5-FU) for the treatment of eyelid squamous cell carcinoma in 5 horses. Equine Veterinary Education, 26: 333-335, 2014.

Robinson, E.N.; Sprayberry, K.A. Current therapy in equine medicine. $6^{\text {th }}$ ed. Philadelphia: Saunders Elsevier, 2008. 639644p.

Scott, D.W.; Miller Jr., W.H. Neoplastic and nonneoplastic tumors. In: Equine dermatology. Saint Louis: Saunders, 2003. 698-795p.

Scott, D.W.; Miller, W.H.J. Dermatologia equina. Buenos Aires: Inter-médica Editorial XXI, 2004. p. 625.

Sundberg, J.P.; Burnstein, T.; Page, E.H.; Kirkham, W.W.; Robinson, F.R. Neoplasms of Equidae. Journal of American Veterinary Medicine Association, 15(170): 150-152, 1977. 